\title{
A Note on Crank-Nicolson Scheme for Burgers’ Equation
}

\author{
Kanti Pandey, Lajja Verma \\ Department of Mathematics and Astronomy, University of Lucknow, Lucknow, India \\ E-mail:pandey_kanti@yahoo.co.in,lajjamaths@yahoo.co.in \\ Received April 5, 2011; revised May 23, 2011; accepted May 26, 2011
}

\begin{abstract}
In this work we generate the numerical solutions of the Burgers' equation by applying the Crank-Nicolson method directly to the Burgers' equation, i.e., we do not use Hopf-Cole transformation to reduce Burgers' equation into the linear heat equation. Absolute error of the present method is compared to the absolute error of the two existing methods for two test problems. The method is also analyzed for a third test problem, numerical solutions as well as exact solutions for different values of viscosity are calculated and we find that the numerical solutions are very close to exact solution.
\end{abstract}

Keywords: Hopf-Cole Transformation, Burgers’ Equation, Crank-Nicolson Scheme, Nonlinear Partial Differential Equations

\section{Introduction}

Burgers' equation is one of the most important nonlinear partial differential equations governed by the following equation

$$
\begin{aligned}
& w_{t}=\left(\frac{v_{d}}{2} w_{x}-\frac{w^{2}}{2}\right)_{x}, \\
& w \equiv w(x, t),(x, t) \in[0,1] \times[0, T] .
\end{aligned}
$$

This equation is nonlinear and can be considered as nonlinear analog of the Navier-Stokes equations. It has a convection term, a diffusion term and a time-dependent term. It also has a large variety of applications in modeling of water in unsaturated oil, dynamics of soil in water, statics of flow problems, mixing and turbulent diffusion, cosmology and seismology [1-3].

With viscous term the Burgers' Equation (1) is parabolic while without viscous term it is hyperbolic. In the later case it possesses discontinuous solutions due to the nonlinear term and even if smooth initial condition is considered the solution may be discontinuous after finite time. It also governs the phenomenon of shock waves [4].

In the present work we consider the Burgers' Equation (1) with the initial condition

$$
w(x, 0)=f(x), \quad 0 \leq x \leq 1,
$$

and the boundary conditions

$$
\begin{array}{ll}
w(0, t)=g_{1}(t), & 0 \leq t \leq T, \\
w(0, t)=g_{2}(t), & 0 \leq t \leq T,
\end{array}
$$

where $v_{d}>0$ is a coefficient of viscous diffusion and $f, g_{1}$ and $g_{2}$ are the sufficiently smooth given functions.

Several researchers have successfully used Burgers' equation to develop new algorithms and to test various existing algorithms. In most of the cases researchers used Hopf-Cole $[5,6]$ transformation to linearize the Burgers' equations into parabolic partial differential equation. Some of the researchers also tried to tackle the nonlinear Burgers' equation directly (without Hopf-Cole). Kadalbajoo et al. [7] applied Crank-Nicolson finite difference method to the linearized Burgers' equation by Hopf-Cole transformation which is unconditionally stable and is second order convergent in both space and time with no restriction on mesh size. Gorguis [8] applied the Adomian decomposition method on the Burgers' equation directly and compared the numerical result with the analytical result. In another result due to Kutluay et al. [9] a direct approach via least square quadratic B-spline finite element method is discussed. Recently Pandey et al. [10] discussed Douglas finite difference scheme on linearized Burgers' equation which is fourth order convergent in space and second order convergent in time.

In this paper we first apply Crank-Nicolson finite difference scheme directly on the nonlinear Equation (1) and derive a nonlinear finite difference scheme, and then use it to derive a system of linear equations which we 
solve by using Mathematica (version 7.0). For two test problems we compare the absolute error of the numerical solutions to the absolute error of the numerical results established by Kadalbajoo et al. [7] and Pandey et al. [10]. For the third test problem we compare our numerical results with the analytical solution. The exact solution for the third problem is calculated on Mathematica (version 7.0).

In this paper we show that it is more appropriate to consider the Burgers' equation directly than reducing it into linear parabolic problem and then discretize it. Therefore this paper is an improvement over the results in [7] and [10].

This paper is divided in 4 sections. In Section 2 we give expression for exact solution by Hopf-Cole transformation which is used to calculate the exact solutions. In the same section we collocate and discretize to get a nonlinear finite difference equation and then through a simple approximation we deduce linear finite difference equation. In Section 3 we give three examples and in Section 4 we demonstrate properties of the computed numerical solutions in the form of Tables 1-11 and Figures 1-4.

\section{Description of the Method}

\subsection{Exact Solution}

Hopf and Cole [5,6] suggested that (1) can be reduced to linear heat equation by the non-linear transformation. Let

$$
\psi=-v_{d}(\log \phi),
$$

and

$$
w=\psi_{x} .
$$

Putting in (1) we get

$$
\psi_{t}+\frac{1}{2} \psi_{x}^{2}=\frac{\nu_{d}}{2} \psi_{x x} .
$$

Next applying the transformation (5) we get

$$
\phi_{t}=\frac{v_{d}}{2} \phi_{x x} \text {. }
$$

The fourier series solution to the linearized heat equation is

$$
\phi(x, t)=A_{0}+\sum_{n=1}^{\infty} A_{n} \exp \left(-\frac{v_{d} n^{2} \pi^{2} t}{2}\right) \cos n \pi x
$$

with fourier coefficients at $t=0$ as

$$
\begin{aligned}
& A_{0}=\int_{0}^{1} E(x) \mathrm{d} x, \\
& A_{n}=2 \int_{0}^{1} E(x) \cos (n \pi x) \mathrm{d} x,
\end{aligned}
$$

where $w_{0}(\xi)=w(\xi, 0)$ and
$E(x)=\exp \left(-\frac{1}{v_{d}} \int_{0}^{x} w_{0}(\xi) \mathrm{d} \xi\right)$. Using the Hopf-Cole transformation we have the exact solution

$$
w(x, t)=\pi v_{d} \frac{\sum_{n=1}^{\infty} A_{n} H_{n}(t) n \sin n \pi x}{A_{0}+\sum_{n=1}^{\infty} A_{n} H_{n}(t) \cos n \pi x}
$$

where $H_{n}(t)=\exp \left(-\frac{v_{d} n^{2} \pi^{2} t}{2}\right)$.

\subsection{Discretization}

First of all we divide the solution space into a uniform mesh. For this we divide the interval $[0,1]$ into $N$ equal subintervals and divide the interval $[0, T]$ into $M$ equal subintervals. Let $h=1 / N$ be the mesh width in space and $x_{i}=i h$ for $i=1(1) N$. Let $k=T / M$ be the mesh width in time and $t_{j}=j k$ for $j=0(1) M$. Now Collocating the Burgers' Equation (1) we get

$$
\begin{aligned}
& \frac{\partial w_{i, j}}{\partial t}+\frac{1}{2} \frac{\partial\left(w_{i, j}\right)^{2}}{\partial x}=\frac{v_{d}}{2} \frac{\partial^{2} w_{i, j}}{\partial x^{2}}, \\
& i=1(1) N, j=0(1) M .
\end{aligned}
$$

where $w_{i, j}=w\left(x_{i}, t_{j}\right)$. The Crank-Nicolson method $[11,12]$ gives the following system of nonlinear equations,

$$
\begin{aligned}
& w_{i, j+1}-w_{i, j}+\frac{1}{2} \frac{k}{h} \mu_{x} \delta_{x}\left(\frac{w_{i, j+1}+w_{i, j}}{2}\right)^{2} \\
& =\frac{v_{d}}{2} \frac{k}{h^{2}} \delta_{x}^{2}\left(\frac{w_{i, j+1}+w_{i, j}}{2}\right) .
\end{aligned}
$$

where $\delta_{x}$ and $\mu_{x}$ are central difference operator and averaging operator respectively. To linearize we put $w_{i, j+1}=w_{i, j}+v_{i, j}$ into (14) where $v_{i, j}=w_{i, j+1}-w_{i, j}$ and neglecting $O\left(v_{i, j}^{2}\right)$ we get

$$
\begin{aligned}
& -\left\{\frac{1}{4} s w_{i-1, j}+\frac{r}{2} \frac{v_{d}}{2}\right\} v_{i-1, j}+\left\{1+r \frac{v_{d}}{2}\right\} v_{i, j} \\
& +\left\{\frac{1}{4} s w_{i+1, j}-\frac{r}{2} \frac{v_{d}}{2}\right\} v_{i+1, j} \\
& =\left\{r \frac{v_{d}}{2}+\frac{1}{4} r w_{i-1, j}\right\} w_{i-1, j}-r v_{d} w_{i, j} \\
& +\left\{r \frac{v_{d}}{2}-\frac{1}{4} s w_{i+1, j}\right\} w_{i+1, j}
\end{aligned}
$$

where $s=(k / h)$ and $r=\left(k / h^{2}\right)$.

\section{Numerical Results and Discussions}

In this section we demonstrate the accuracy of the 
present method by solving three test problems and compare the results with the two existing results. The computations are performed using Mathematica 7.0 and Origin 7.5 .

\subsection{Problem 1}

Consider Equation (1) with boundary conditions and initial condition as

$$
\begin{gathered}
w(0, t)=w(1, t)=0, t>0, \\
w(x, 0)=\sin \pi x,
\end{gathered}
$$

where $\left(v_{d}\right) / 2$ is the coefficient of kinematic viscosity. We substitute

$$
w(x, t)=\frac{-v_{d} \phi_{x}}{\phi}
$$

in Equation (1) and get $\phi_{t}=\frac{\nu_{d}}{2} \phi_{x x}, 0<x<1, t>0$ with initial condition

$$
\phi(x, 0)=\exp \left(\frac{-1}{\pi v_{d}}(1-\cos \pi x)\right), 0<x<1 .
$$

and boundary condition

$$
\phi_{x}(0, t)=\phi_{x}(1, t)=0, t>0 .
$$

The exact solution of the Burgers' Equation (1) is (12) with given Fourier coefficients:

$$
\begin{aligned}
& A_{0}=\int_{0}^{1} \exp \left(\frac{-1}{\pi v_{d}}(1-\cos \pi x)\right) \mathrm{d} x \\
& A_{n}=2 \int_{0}^{1} \exp \left(\frac{-1}{\pi v_{d}}(1-\cos \pi x) \cos n \pi x\right) \mathrm{d} x
\end{aligned}
$$

\subsection{Problem 2}

As a second example consider (1) with the boundary conditions (16) and initial condition

$$
w(x, 0)=4 x(1-x), 0<x<1 .
$$

The exact solution (12) can be obtained in the similar fashion as in Problem 3.1 with the Fourier coefficients as follows :

$$
\begin{aligned}
& A_{0}=\int_{0}^{1} \exp \left(\frac{-2 x^{2}}{3 v_{d}}(3-2 x)\right) \mathrm{d} x \\
& A_{n}=2 \int_{0}^{1} \exp \left(\frac{-2 x^{2}}{3 v_{d}}(3-2 x)\right) \cos (n \pi x) \mathrm{d} x .
\end{aligned}
$$

\subsection{Problem 3}

Consider Equation (1) with boundary conditions (16) and initial condition

$$
w(x, 0)=\frac{2 \pi \sin \pi x}{2+\cos \pi x}, \quad 0<x<1 .
$$

The exact solution can be calculated by using the formula (12) where

$$
\begin{aligned}
& A_{0}=\int_{0}^{1}\left(\frac{2+\cos \pi x}{2}\right)^{2 / v} d x \\
& A_{n}=2 \int_{0}^{1}\left(\frac{2+\cos \pi x}{2}\right)^{2 / v} \cos n \pi x d x .
\end{aligned}
$$

\section{Conclusions}

We present Crank-Nicolson finite difference scheme for Burgers' equation without Hopf-Cole transformation. We claim that it is better to solve the nonlinear Burgers' equation directly, i.e., without reducing it to linear heat equation by Hopf-Cole transformation. Our claim is very well supported by the Tables 1-10 and Graphs 1-3. From Table 11 and Graph 4 it is also proved that numerical results are in good agreement with the analytical solution. The exact solution for the Problem 3.3 is calculated by using Mathematica 7.0. Figure 4 also depicts the physical behavior of the solutions and thus behavior of any physical system governed by Burgers' equation can be studied by this method.

\subsection{Tables}

Computed results are displayed in Tables $\mathbf{1}$ to $\mathbf{1 1}$ at different nodal points for different values of viscosity. In Tables 1 to $\mathbf{6}$ we compare the absolute error with the absolute error of $[7,10]$ for the Problem 3.1. From Table $\mathbf{7}$ to Table 10 absolute error is compared to the absolute

Table 1. Comparison of the absolute error with the absolute error of $[7,10]$ for Problem 3.1 at $T=0.01$, for $v_{d}=20$ and $K$ $=0.0001$ for $N=40$.

\begin{tabular}{cccc}
\hline$x /$ Error & $\begin{array}{c}\text { Without } \\
\text { Hopf-Cole }\end{array}$ & Kadalbajoo et al. & Pandey et al. \\
\hline 0.1 & $5.78801 \mathrm{E}-05$ & $6 \mathrm{E}-05$ & 0.00016 \\
0.2 & 0.000109996 & 0.00011 & 0.00031 \\
0.3 & 0.000151182 & 0.00016 & 0.00044 \\
0.4 & 0.000177403 & 0.00019 & 0.00051 \\
0.5 & 0.000186149 & 0.0002 & 0.00054 \\
0.6 & 0.000176667 & 0.00019 & 0.00051 \\
0.7 & 0.000149991 & 0.00016 & 0.00044 \\
0.8 & 0.000108805 & 0.00011 & 0.00031 \\
0.9 & $5.71442 \mathrm{E}-05$ & $6 \mathrm{E}-05$ & 0.00016 \\
\hline
\end{tabular}


Table 2. Comparison of the absolute error with the absolute error of $[7,10]$ for Problem 3.1 at $T=0.01$, for $v_{d}=20$ and $K$ $=\mathbf{0 . 0 0 0 1}$ for $N=\mathbf{8 0}$.

\begin{tabular}{cccc}
\hline$x$ /Error & $\begin{array}{c}\text { Without } \\
\text { Hopf-Cole }\end{array}$ & Kadalbajoo et al. & Pandey et al. \\
\hline 0.1 & $1.37807 \mathrm{E}-05$ & $1 \mathrm{E}-05$ & $7 \mathrm{E}-05$ \\
0.2 & $2.61869 \mathrm{E}-05$ & $3 \mathrm{E}-05$ & 0.00014 \\
0.3 & $3.59876 \mathrm{E}-05$ & $5 \mathrm{E}-05$ & 0.00021 \\
0.4 & $4.22225 \mathrm{E}-05$ & $5 \mathrm{E}-05$ & 0.00024 \\
0.5 & $4.42961 \mathrm{E}-05$ & $6 \mathrm{E}-05$ & 0.00025 \\
0.6 & $4.20319 \mathrm{E}-05$ & $5 \mathrm{E}-05$ & 0.00024 \\
0.7 & $3.56792 \mathrm{E}-05$ & $5 \mathrm{E}-05$ & 0.00021 \\
0.8 & $2.58784 \mathrm{E}-05$ & $3 \mathrm{E}-05$ & 0.00014 \\
0.9 & 0.00001359 & $1 \mathrm{E}-05$ & $8 \mathrm{E}-05$ \\
\hline
\end{tabular}

Table 3. Comparison of the absolute error with the absolute error of $[7,10]$ for Problem 3.1 at $T=0.1$, for $v_{d}=2$ and $K=$ 0.001 for $N=40$.

\begin{tabular}{cccc}
\hline$x$ /Error & $\begin{array}{c}\text { Without } \\
\text { Hopf-Cole }\end{array}$ & $\begin{array}{c}\text { Kadalbajoo et } \\
\text { al. }\end{array}$ & $\begin{array}{c}\text { Pandey et } \\
\text { al. }\end{array}$ \\
\hline 0.1 & $6.10384 \mathrm{E}-05$ & $6 \mathrm{E}-05$ & 0.00016 \\
0.2 & 0.0001156 & 0.00011 & 0.0003 \\
0.3 & 0.000157849 & 0.00016 & 0.00042 \\
0.4 & 0.00018329 & 0.00018 & 0.0005 \\
0.5 & 0.000189452 & 0.0002 & 0.00054 \\
0.6 & 0.000176365 & 0.00019 & 0.00052 \\
0.7 & 0.000146518 & 0.00017 & 0.00045 \\
0.8 & 0.000104112 & 0.00048 & 0.00033 \\
0.9 & $5.38605 \mathrm{E}-05$ & 0.00026 & 0.00018 \\
\hline
\end{tabular}

Table 4. Comparison of the absolute error with the absolute error of $[7,10]$ for Problem 3.1 at $T=0.1$, for $v_{d}=2$ and $K=$ 0.001 for $N=80$.

\begin{tabular}{cccc}
\hline$x$ /Error & $\begin{array}{c}\text { Without } \\
\text { Hopf-Cole }\end{array}$ & Kadalbajoo et al. & Pandey et al. \\
\hline 0.1 & $1.45914 \mathrm{E}-05$ & $2 \mathrm{E}-05$ & $7 \mathrm{E}-05$ \\
0.2 & $2.76247 \mathrm{E}-05$ & $3 \mathrm{E}-05$ & 0.00014 \\
0.3 & $3.76962 \mathrm{E}-05$ & $4 \mathrm{E}-05$ & 0.0002 \\
0.4 & $4.37257 \mathrm{E}-05$ & $4 \mathrm{E}-05$ & 0.00023 \\
0.5 & $4.51272 \mathrm{E}-05$ & $5 \mathrm{E}-05$ & 0.00025 \\
0.6 & $4.19278 \mathrm{E}-05$ & $5 \mathrm{E}-05$ & 0.00024 \\
0.7 & $3.47543 \mathrm{E}-05$ & $5 \mathrm{E}-05$ & 0.00021 \\
0.8 & 0.000024642 & $3 \mathrm{E}-05$ & 0.00016 \\
0.9 & $1.27275 \mathrm{E}-05$ & $2 \mathrm{E}-05$ & $8 \mathrm{E}-05$ \\
\hline
\end{tabular}

Table 5. Comparison of the absolute error with the absolute error of $[7,10]$ for Problem 3.1 for $v_{d}=20, K=0.01, N=80$ at different times.

\begin{tabular}{cccc}
\hline$x$ /Error & $\begin{array}{c}\text { Without } \\
\text { Hopf-Cole }\end{array}$ & Kadalbajoo et al. & Pandey et al. \\
\hline 0.4 & $5.9 \mathrm{E}-05$ & $8.00 \mathrm{E}-05$ & 0.00023 \\
0.6 & $4.4 \mathrm{E}-05$ & $5.00 \mathrm{E}-05$ & 0.00016 \\
1 & $4 \mathrm{E}-05$ & $2.00 \mathrm{E}-05$ & $8 \mathrm{E}-05$ \\
3 & $1.48 \mathrm{E}-05$ & 0 & $1 \mathrm{E}-05$ \\
0.4 & 0.000118 & $8.00 \mathrm{E}-05$ & 0.00029 \\
0.6 & $9.5 \mathrm{E}-05$ & $7.00 \mathrm{E}-05$ & 0.00024 \\
1 & $7.1 \mathrm{E}-05$ & $4.00 \mathrm{E}-05$ & 0.00015 \\
3 & $2.39 \mathrm{E}-05$ & $1.00 \mathrm{E}-05$ & $2 \mathrm{E}-05$ \\
0.4 & $3.7 \mathrm{E}-05$ & $4.00 \mathrm{E}-05$ & 0.00021 \\
0.6 & $7.5 \mathrm{E}-05$ & $6.00 \mathrm{E}-05$ & 0.00021 \\
1 & $7.2 \mathrm{E}-05$ & $3.00 \mathrm{E}-05$ & 0.00015 \\
3 & 0.0010165 & 0.00101 & 0.0002 \\
\hline
\end{tabular}

Table 6. Comparison of the absolute error with the absolute error of $[7,10]$ for Problem 3.1 for $v_{d}=0.02, K=0.01, N=$ 80 at different times.

\begin{tabular}{cccc}
\hline$x /$ Error & $\begin{array}{c}\text { Without } \\
\text { Hopf-Cole }\end{array}$ & $\begin{array}{c}\text { Kadalbajoo et } \\
\text { al. }\end{array}$ & Pandey et al. \\
\hline 0.4 & $7.2 \mathrm{E}-05$ & 0.00038 & 0.00076 \\
0.6 & $5 \mathrm{E}-05$ & $6 \mathrm{E}-05$ & 0.00012 \\
1 & $2.7 \mathrm{E}-05$ & $2 \mathrm{E}-05$ & 0.00013 \\
3 & $8 \mathrm{E}-06$ & 0 & $6 \mathrm{E}-05$ \\
0.4 & 0.000167 & 0.00726 & 0.01517 \\
0.6 & 0.000106 & 0.00269 & 0.00736 \\
1 & $5.2 \mathrm{E}-05$ & 0.00058 & 0.00229 \\
3 & $7 \mathrm{E}-06$ & 0 & $4 \mathrm{E}-05$ \\
0.4 & 0.000384 & 0.02654 & 0.04398 \\
0.6 & 0.000234 & 0.01 & 0.02528 \\
1 & $9.6 \mathrm{E}-05$ & 0.00228 & 0.0093 \\
3 & $3.3 \mathrm{E}-05$ & 0 & 0.00047 \\
\hline
\end{tabular}

Table 7. Comparison of the absolute error with the absolute error of $[7,10]$ for Problem 3.2 at $T=0.1$, for $v_{d}=2$ and $K=$ 0.001 for $N=40$.

\begin{tabular}{clll}
\hline$x$ /Error & $\begin{array}{l}\text { Without } \\
\text { Hopf-Cole }\end{array}$ & $\begin{array}{l}\text { Kadalbajoo } \\
\text { al. }\end{array}$ & $\begin{array}{l}\text { Pandey } \\
\text { al. }\end{array}$ \\
\hline 0.1 & $6.34389 \mathrm{E}-05$ & $6 \mathrm{E}-05$ & 0.00012 \\
0.2 & 0.000119993 & 0.00011 & 0.00023 \\
0.3 & 0.000163549 & 0.00016 & 0.00032 \\
0.4 & 0.00018952 & 0.00019 & 0.00037 \\
0.5 & 0.000195514 & 0.0002 & 0.00039 \\
0.6 & 0.000181726 & 0.0002 & 0.00038 \\
0.7 & 0.000150809 & 0.00017 & 0.00033 \\
0.8 & 0.000107093 & 0.00012 & 0.00024 \\
0.9 & $5.53858 \mathrm{E}-05$ & $7 \mathrm{E}-05$ & 0.00013 \\
\hline
\end{tabular}


Table 8. Comparison of the absolute error with the absolute error of $[7,10]$ for Problem 3.2 at $T=0.1$, for $v_{d}=2$ and $K=$ 0.001 for $N=80$.

\begin{tabular}{cccc}
\hline$x$ /Error & $\begin{array}{c}\text { Without } \\
\text { Hopf-Cole }\end{array}$ & $\begin{array}{c}\text { Kadalbajoo et } \\
\text { al. }\end{array}$ & $\begin{array}{c}\text { Pandey et } \\
\text { al. }\end{array}$ \\
\hline 0.1 & 0.000015144 & $1 \mathrm{E}-05$ & $3 \mathrm{E}-05$ \\
0.2 & $2.86478 \mathrm{E}-05$ & $3 \mathrm{E}-05$ & $6 \mathrm{E}-05$ \\
0.3 & $3.90448 \mathrm{E}-05$ & $5 \mathrm{E}-05$ & $9 \mathrm{E}-05$ \\
0.4 & $4.52233 \mathrm{E}-05$ & $5 \mathrm{E}-05$ & $9 \mathrm{E}-05$ \\
0.5 & 0.000046599 & $5 \mathrm{E}-05$ & $1 \mathrm{E}-04$ \\
0.6 & $4.32271 \mathrm{E}-05$ & $5 \mathrm{E}-05$ & $1 \mathrm{E}-04$ \\
0.7 & $3.57791 \mathrm{E}-05$ & $5 \mathrm{E}-05$ & $9 \mathrm{E}-05$ \\
0.8 & $2.53375 \mathrm{E}-05$ & $3 \mathrm{E}-05$ & $6 \mathrm{E}-05$ \\
0.9 & $1.30758 \mathrm{E}-05$ & $2 \mathrm{E}-05$ & $3 \mathrm{E}-05$ \\
\hline
\end{tabular}

Table 9. Comparison of the absolute error with the absolute error of $[7,10]$ for Problem 3.2 for $v_{d}=0.2, K=0.01, N=80$ at different times.

\begin{tabular}{cccc}
\hline$x$ /Error & $\begin{array}{c}\text { Without } \\
\text { Hopf-Cole }\end{array}$ & Kadalbajoo et al. & Pandey et al. \\
\hline 0.4 & $6.3 \mathrm{E}-05$ & $9 \mathrm{E}-05$ & 0.00017 \\
0.6 & $4.6 \mathrm{E}-05$ & $5 \mathrm{E}-05$ & 0.00011 \\
1 & $3.5 \mathrm{E}-05$ & $2 \mathrm{E}-05$ & $6 \mathrm{E}-05$ \\
3 & $1.16 \mathrm{E}-05$ & 0 & $1 \mathrm{E}-05$ \\
0.4 & 0.000118 & $8 \mathrm{E}-05$ & 0.00013 \\
0.6 & 0.000101 & $7 \mathrm{E}-05$ & 0.00012 \\
1 & $8.1 \mathrm{E}-05$ & $3 \mathrm{E}-05$ & $8 \mathrm{E}-05$ \\
3 & $2.46 \mathrm{E}-05$ & $1 \mathrm{E}-05$ & $1 \mathrm{E}-05$ \\
0.4 & $3.6 \mathrm{E}-05$ & $4 \mathrm{E}-05$ & $8 \mathrm{E}-05$ \\
0.6 & $7.1 \mathrm{E}-05$ & $7 \mathrm{E}-05$ & $3 \mathrm{E}-05$ \\
1 & $6.8 \mathrm{E}-05$ & $4 \mathrm{E}-05$ & $6 \mathrm{E}-05$ \\
3 & $1.45 \mathrm{E}-05$ & 0 & $1 \mathrm{E}-05$ \\
\hline
\end{tabular}

Table 10. Comparison of the absolute error with the absolute error of $[7,10]$ for Problem 3.2 for $v_{d}=0.02, K=$ $0.01, N=80$ at different times.

\begin{tabular}{cccc}
\hline$x$ /Error & $\begin{array}{c}\text { Without } \\
\text { Hopf-Cole }\end{array}$ & $\begin{array}{c}\text { Kadalbajoo et } \\
\text { al. }\end{array}$ & Pandey et al. \\
\hline 0.4 & 0.00012 & 0.00047 & 0.00113 \\
0.6 & $8.6 \mathrm{E}-05$ & $8 \mathrm{E}-05$ & 0.00024 \\
1 & $4.9 \mathrm{E}-05$ & $2 \mathrm{E}-05$ & 0.00011 \\
3 & $1.21 \mathrm{E}-05$ & 0 & $6 \mathrm{E}-05$ \\
0.4 & 0.000167 & 0.00818 & 0.0172 \\
0.6 & 0.000128 & 0.00293 & 0.00839 \\
1 & $7.7 \mathrm{E}-05$ & 0.00059 & 0.00258 \\
3 & $1.6 \mathrm{E}-05$ & 0 & $5 \mathrm{E}-05$ \\
0.4 & 0.000286 & 0.0289 & 0.04617 \\
0.6 & 0.000212 & 0.011 & 0.02718 \\
1 & 0.000109 & 0.00238 & 0.0101 \\
3 & $4.4 \mathrm{E}-05$ & $4 \mathrm{E}-05$ & 0.0005 \\
\hline
\end{tabular}

Table 11. Comparison of the numerical solution with the exact solution for Problem 3.3 at different space points at $T$ $=0.01$, for $v_{d}=20$ and $K=0.0001$ for different values of $N$.

\begin{tabular}{cccccc}
\hline$x$ & $N=10$ & $N=20$ & $N=40$ & $N=80$ & Exact \\
\hline 0.1 & 0.36871 & 0.377309 & 0.370262 & 0.370173 & 0.370141 \\
0.2 & 0.705991 & 0.720825 & 0.708758 & 0.708574 & 0.70851 \\
0.3 & 0.981812 & 0.99888 & 0.985219 & 0.984931 & 0.984834 \\
0.4 & 1.16936 & 1.18429 & 1.17275 & 1.17236 & 1.17224 \\
0.5 & 1.24751 & 1.25697 & 1.25035 & 1.24988 & 1.24973 \\
0.6 & 1.20385 & 1.20667 & 1.20583 & 1.20532 & 1.20517 \\
0.7 & 1.03763 & 1.0351 & 1.03875 & 1.03827 & 1.03813 \\
0.8 & 0.761828 & 0.757042 & 0.762304 & 0.761929 & 0.761818 \\
0.9 & 0.403226 & 0.399692 & 0.403361 & 0.403154 & 0.403094 \\
\hline
\end{tabular}

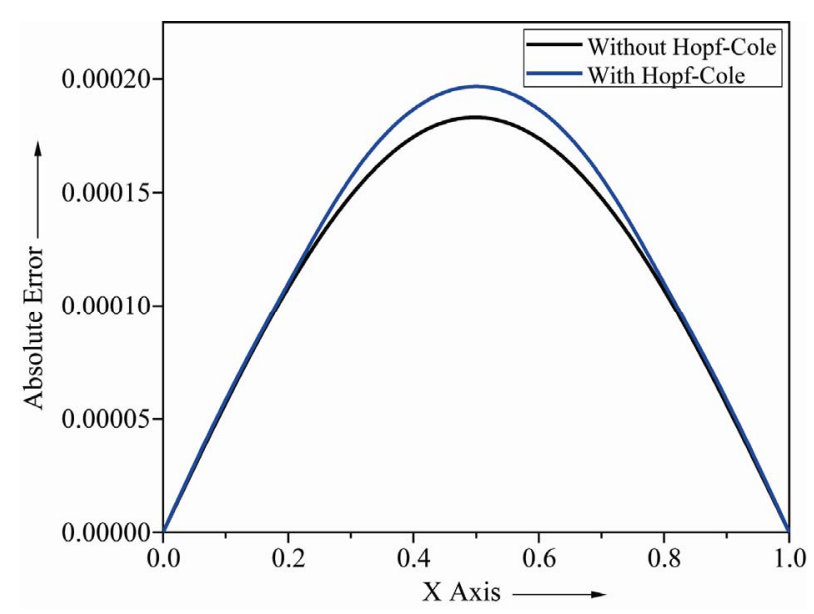

(a)

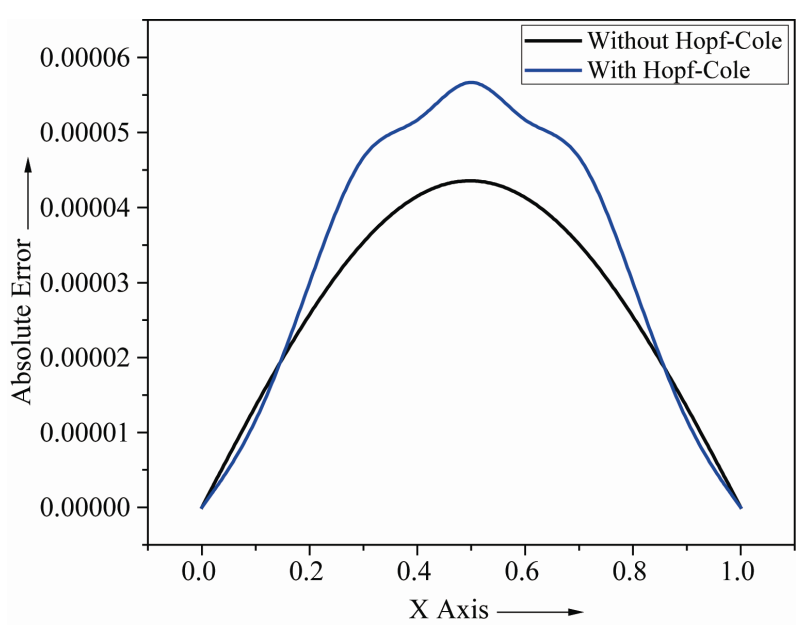

(b)

Figure 1. Absolute errors of Problem 3.1 at different times for $v_{d}=20$ and $K=0.0001$, (a) $N=40$, (b), $N=80$. 


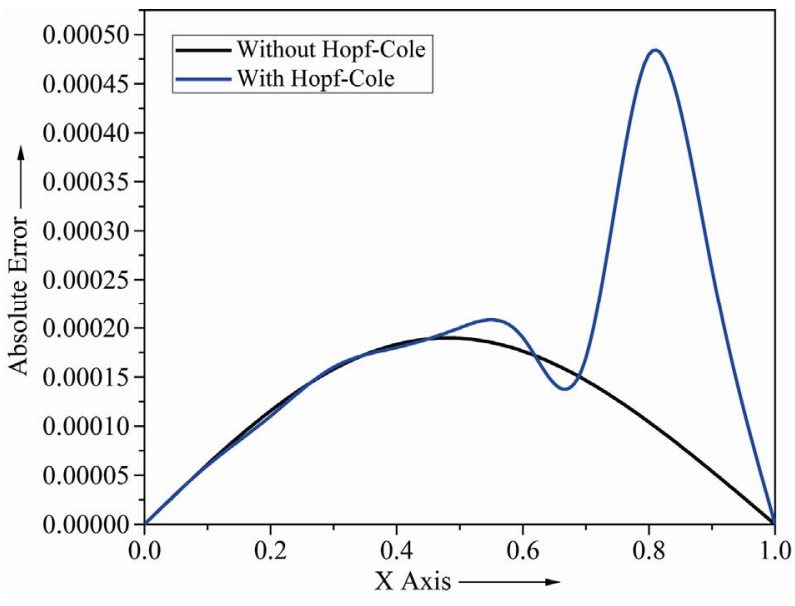

(a)

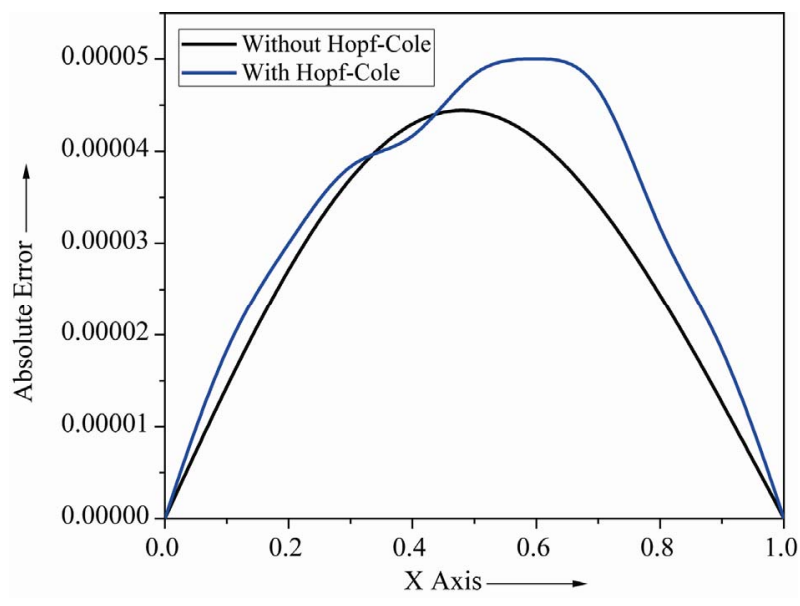

(b)

Figure 2. Absolute errors of Problem 3.1 at different times for $v_{d}=2$ and $K=0.001$, (a) $N=40$, (b) $N=80$.

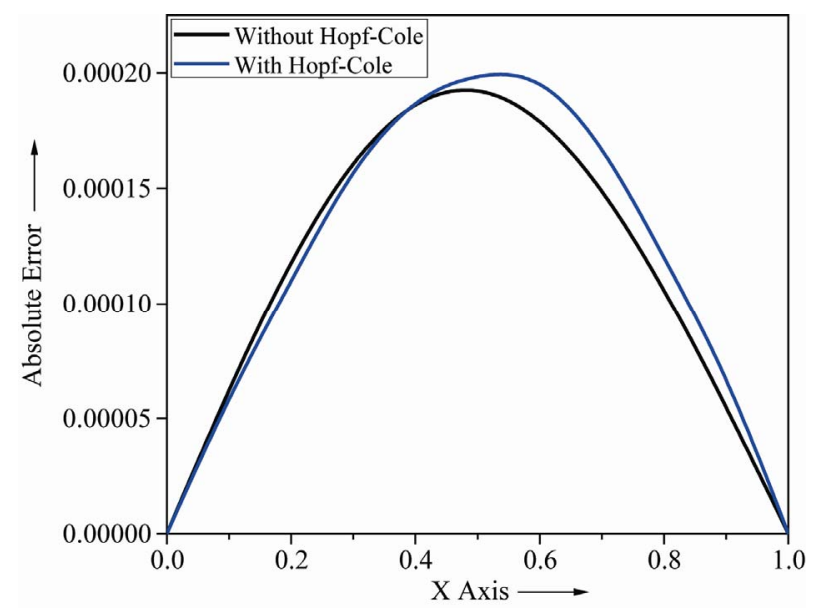

(a)

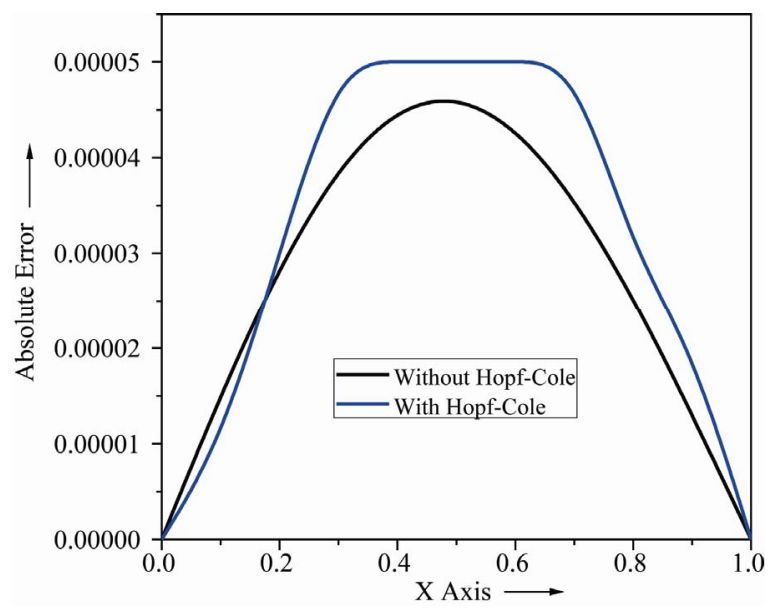

(b)

Figure 3. Absolute errors of Problem 3.2 at different times for $v_{d}=2$ and $K=0.001$, (a) $N=40$, (b) $N=80$.

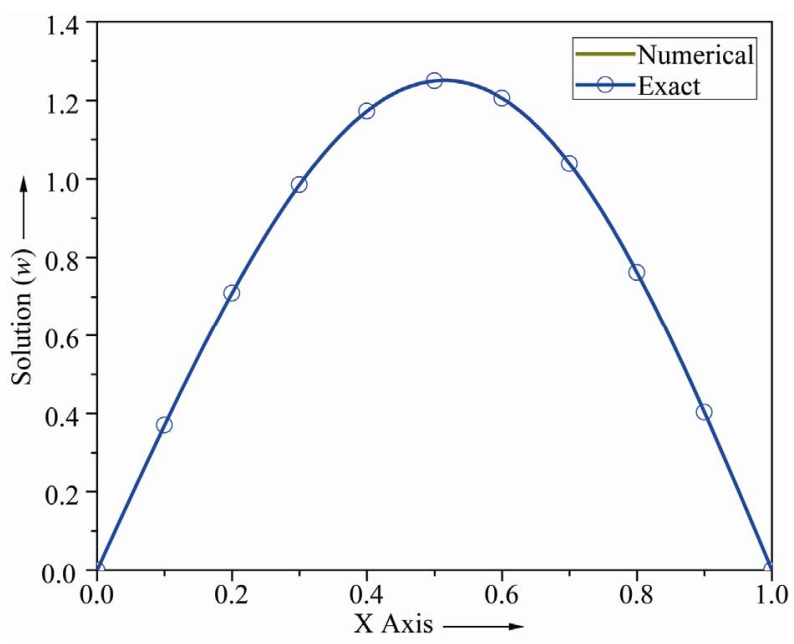

(a)

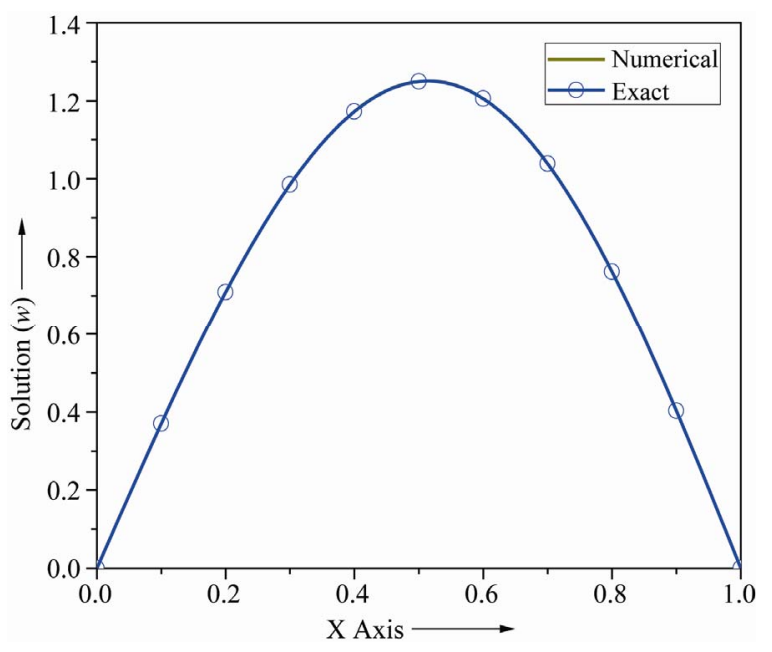

(b)

Figure 4. Numerical solutions of Problem 3.3 at different times for $v_{d}=2$ and $K=0.001$, (a) $N=40,(b) N=80$. 
error of $[7,10]$ for the Problem 3.2. In Table 11 for Problem 3.3 we compare the numerical solution to the exact solution and it is observed that computed result shows greater agreement with the exact solution as the mesh size is refined.

\subsection{Figures}

In Figures 1 and 2 we compare the absolute error with the absolute error of [7] for Problem 3.1 and in Figure 3 we compare the absolute error with the absolute error of [7] for Problem 3.2. Finally in Figure 4 we compare the exact solution with the numerical solution for Problem 3.3.

\section{References}

[1] N. Su, J. P. C. Watt, K. W. Vincent, M. E. Close and R. Mao, "Analysis of Turbulent Flow Patterns of Soil Water under Field Conditions Using Burgers' Equation and Porous Suction-Cup Samplers," Australian Journal of Soil Research, Vol. 42, No. 1, 2004, pp. 9-16. doi:10.1071/SR02142

[2] N. J. Zabusky and M. D. Kruskal, "Interaction of Solitons in a Collisionless Plasma and the Recurrence of Initial States," Physical Review, Vol. 15, No. 6, 1965, pp. 240-243. doi:10.1088/0305-4470/33/18/308

[3] P. F. Zhao and M. Z. Qin, "Multisymplectic Geometry and Multisymplectic Preissmann Scheme for the Kdv Equation," Journal of Physics A, Vol. 33, No. 18, 2000, pp. 3613-3626.

[4] H. Brezis and F. Browder, "Partial Differential Equations in the 20th Century," Advances in Mathematics, Vol. 135, No. 1, 1998, pp. 76-144. doi:10.1006/aima.1997.1713

[5] J. D. Cole, "On a Quasilinear Parabolic Equation Occurring in Aerodynamics," Quarterly of Applied Mathematics, Vol. 9, 1951, pp. 225-236.

[6] E. Hopf, "The Partial Differential Eqaution $u_{t}+u u_{x}=$ $v u_{x x}$," Communications on Pure and Applied Mathematics, Vol. 3, 1950, pp. 201-230. doi:10.1002/cpa.3160030302

[7] M. K. Kadalbajoo and A. Awasthi, "A Numerical Method Based on Crank-Nicolson Scheme for Burgers' Equation," Applied Mathematics and Computation, Vol. 182, No. 2, 2006, pp. 1430-1442. doi:10.1016/j.amc.2006.05.030

[8] A. Gorguis, "A Comparison between Cole-Hopf Transformation and Decomposition Method for Solving Burgers' Equations," Applied Mathematics and Computation, Vol. 173, No. 1, 2006, pp. 126-136. doi:10.1016/j.amc.2005.02.045

[9] S. Kutluay, A. Esen and I. Dag, "Numerical Solutions of the Burgers' Equation by the Least-Squares Quadratic B-Spline Finite Element Method," Journal of Computational and Applied Mathematics, Vol. 167, No. 1, 2004, pp. 21-33. doi:10.1016/j.cam.2003.09.043

[10] K. Pandey, L. Verma and A. K. Verma, "On a Finite Difference Scheme for Burgers' Equation," Applied Mathematics and Computation, Vol. 215, No. 6, 2009, pp. 2206-2214. doi:10.1016/j.amc.2009.08.018

[11] M. K. Jain, "Numerical Solution of Differential Equations," New Age International (P) Limited, New Delhi, 1984.

[12] G. D. Smith, "Numerical Solution of Partial Differential Equations," Oxford University Press, Oxford, 1978. 